Article

\title{
Mineral Classification of Makhtesh Ramon in Israel Using Hyperspectral Longwave Infrared (LWIR) Remote-Sensing Data
}

\section{Gila Notesco *, Yaron Ogen and Eyal Ben-Dor}

Remote Sensing Laboratory, Tel Aviv University, Tel Aviv 69978, Israel;

E-Mails: yaronogen@gmail.com (Y.O.); bendor@post.tau.ac.il (E.B.-D.)

* Author to whom correspondence should be addressed; E-Mail: gilano@post.tau.ac.il; Tel.: +972-3640-5679; Fax: +972-3640-5737.

Academic Editors: James Jin-King Liu, Yu-Chang Chan, Magaly Koch and Prasad S. Thenkabail Received: 21 June 2015 / Accepted: 11 September 2015 / Published: 21 September 2015

\begin{abstract}
Hyperspectral remote-sensing techniques offer an efficient procedure for mineral mapping, with a unique hyperspectral remote-sensing fingerprint in the longwave infrared spectral region enabling identification of the most abundant minerals in the continental crust - quartz and feldspars. This ability was examined by acquiring airborne data with the AisaOWL sensor over the Makhtesh Ramon area in Israel. The at-sensor radiance measured from each pixel in a longwave infrared image represents the emissivity, expressing chemical and physical properties such as surface mineralogy, and the atmospheric contribution which is expressed differently during the day and at night. Therefore, identifying similar features in day and night radiance enabled identifying the major minerals in the surface - quartz, silicates (feldspars and clay minerals), gypsum and carbonates - and mapping their spatial distribution. Mineral identification was improved by applying the radiance of an in situ surface that is featureless for minerals but distinctive for the atmospheric contribution as a gain spectrum to each pixel in the image, reducing the atmospheric contribution and emphasizing the mineralogical features. The results were in agreement with the mineralogy of selected rock samples collected from the study area as derived from laboratory X-ray diffraction analysis. The resulting mineral map of the major minerals in the surface was in agreement with the geological map of the area.
\end{abstract}


Keywords: hyperspectral remote-sensing; longwave infrared image; emissivity; Makhtesh Ramon; mineral classification

\section{Introduction}

Most minerals in the Earth's crust present spectral features in the thermal infrared (TIR) region, mainly in the longwave infrared (LWIR) 8.0-13 $\mu \mathrm{m}$ range. Technological developments in Earth-observation remote-sensing tools have positioned multi- and hyper-spectral remote sensing in the LWIR region as a useful tool for mineral mapping using ground, airborne and spaceborne sensors [1-5]. Several algorithms, normalized emissivity procedure (NEM) [6], adjusted normalized emissivity procedure (ANEM) [7], stepwise refining temperature and emissivity separation (SRTES) [8], and in-scene atmospheric compensation procedure (ISAC) [9], among others, have been applied to multispectral and hyperspectral LWIR data to correct for atmosphere and calculate the surface emissivity, an important variable for mineral mapping. We present an optional procedure that can be applied to hyperspectral LWIR images to identify minerals in the surface by comparing day and night spectral features in the at-sensor radiance, without the need to correct for atmosphere. The basis of the procedure is the different expression of the atmospheric contribution to the at-sensor radiance, measured from a surface characterized by low thermal inertia, during the day and at night. In the daytime, some of the radiation emitted from the hot surface is absorbed by the atmosphere, while at night, when the surface becomes as cold as the atmosphere or colder, the emission from the atmospheric gases adds to the radiation emitted from the surface. On the other hand, the expression of the surface mineralogy is similar during the day and at night. Therefore, locating similar features in both day and night at-sensor radiance spectra may assist in identifying minerals in the surface. As a case study, we apply the procedure to day and night data, acquired with the hyperspectral LWIR airborne sensor, AisaOWL (Specim), for mineral mapping. The data were acquired during the first hyperspectral remote sensing (HRS) LWIR airborne campaign in Israel, over Makhtesh Ramon, the largest erosion cirque in the world, consisting of a variety of well-known geological units.

\section{Tools and Methods}

\subsection{The Study Area}

The increasing use of HRS technology in the LWIR spectral region, alongside the visible-near-infrared-shortwave-infrared (VNIR-SWIR, 0.4-2.5 $\mu \mathrm{m}$ ) region, in environmental research, calls for an ideal worldwide calibration site. Makhtesh Ramon cirque is one of the most interesting and powerful sites for HRS sensor calibration, being an arid area with very low humidity, extremely sparse vegetation and clear skies most of the year. The cirque (Figure 1a) is located in the Negev Desert in Southern Israel; it is $40 \mathrm{~km}$ long and $7 \mathrm{~km}$ wide, with a total area of about $200 \mathrm{~km}^{2}$. The minimum elevation at the bottom surface is about $400 \mathrm{~m}$ above sea level, with cliffs at 600-900 $\mathrm{m}$ above sea level surrounding it on all sides. The bottom surface consists of a variety of geological units, including sandstone, gypsum, limestone, dolomite and plutonic crystalline rocks [10], as shown in Figure 1b. 

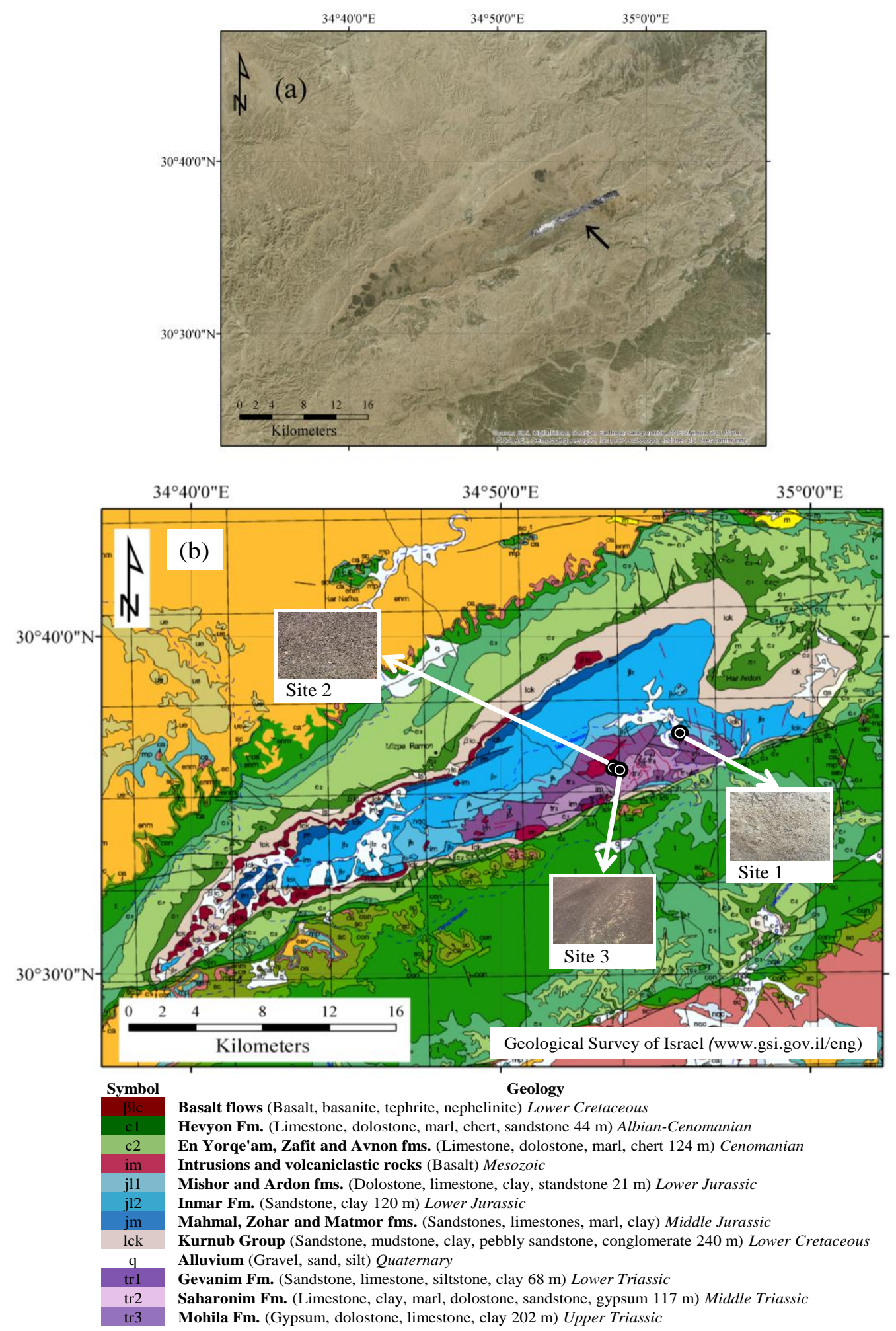

Figure 1. (a) The study area (image source: Esri, DigitalGlobe, GeoEye, Earthstar Geographics, CNES/Airbus DS, USDA, USGS, AEX, Getmapping, Aerogrid, IGN, IGP, swisstopo, and the GIS User Community); arrow indicates the acquired LWIR image (band $10.60 \mu \mathrm{m}$, day image); (b) Geological map of the area (source: Geological Survey of Israel). The photographs show the surface of about 4 square meters of three sites, out of seventeen sites, which were sampled for the ground truth dataset, as described in Section 2.3. 


\subsection{The Airborne Data}

The airborne data were acquired with Specim's AisaOWL hyperspectral sensor, covering the LWIR spectral region $(7.7-12 \mu \mathrm{m})$ with 100 spectral bands and a spectral resolution of $100 \mathrm{~nm}$ [11], on 1 June 2013 at 10:00 and 20:40 UTC. The flight altitude was $1.8 \mathrm{~km}$ above ground level, resulting in a spatial resolution of $2 \mathrm{~m}$. The flight line, shown in Figure 1a, covered an area of about $8 \mathrm{~km}^{2}$ of the bottom surface of the cirque. The elevation across the entire flight line was $475 \pm 50 \mathrm{~m}$ above sea level.

\subsection{Field and Laboratory Measurements}

Ground temperature was measured at several sites using a Fluke 62 MAX infrared thermometer simultaneously with the airborne data acquisition. Daytime temperatures of $40-60{ }^{\circ} \mathrm{C}$ were measured (bright-dark surface, respectively) and nighttime temperatures were $22-24{ }^{\circ} \mathrm{C}$. Air temperatures were $32-22{ }^{\circ} \mathrm{C}$, daytime-nighttime, respectively, as recorded in the nearby areas by the Israel Meteorological Service [12].

In addition, samples of material from the surface were collected at selected sites in the study area, representing different geological units. Each sample represents hundreds of square meters of a uniform surface, represented in the LWIR image by a region of interest (ROI) consisting of more than 10 pixels. Their mineralogy was measured for the ground truth dataset with an X-ray diffractometer at the Wolfson Applied Materials Research Centre at Tel-Aviv University. X-ray diffraction (XRD) data were collected in symmetric Bragg-Brentano geometry with $\mathrm{CuK} \alpha$ radiation on a Bruker D8 Discover $\Theta-\Theta$ X-ray diffractometer equipped with a one-dimensional LynxEye detector based on compound silicon strip technology.

\subsection{Data Analysis}

The at-sensor radiance measured from a rocky surface can be approximated as the radiance from a blackbody surface. Therefore, the at-sensor radiance of each pixel in the day and night LWIR images was fitted with a tangent blackbody radiation curve, as shown in Figure 2a,b, for three ROIs representing the three sites shown in Figure 1b, by using an IDL algorithm as described previously [13]. The algorithm calculates the temperature for each pixel by applying the at-sensor radiance value of the first wavelength to Planck's law. Once the temperature is known, the algorithm calculates the blackbody radiation curve for every wavelength. Then, the algorithm checks that the blackbody radiation curve is higher than the at-sensor radiance at each wavelength. If the calculated curve is not higher at one of the wavelengths, the process is repeated for the second wavelength and so on. In some cases, all calculated blackbody radiation curves tangential to the at-sensor radiance are lower at all wavelengths. In this case, an approximated blackbody radiation curve needs to be calculated. The algorithm finds the maximum value of the at-sensor radiance, calculates the blackbody radiation curve accordingly, and checks if it is higher at all wavelengths. If it is not, it adds $0.05 \mathrm{~K}$ to the temperature and calculates the blackbody radiation curve again in an iterative function until it finds the curve that is higher at all wavelengths, which will serve as the approximate blackbody radiation curve. 

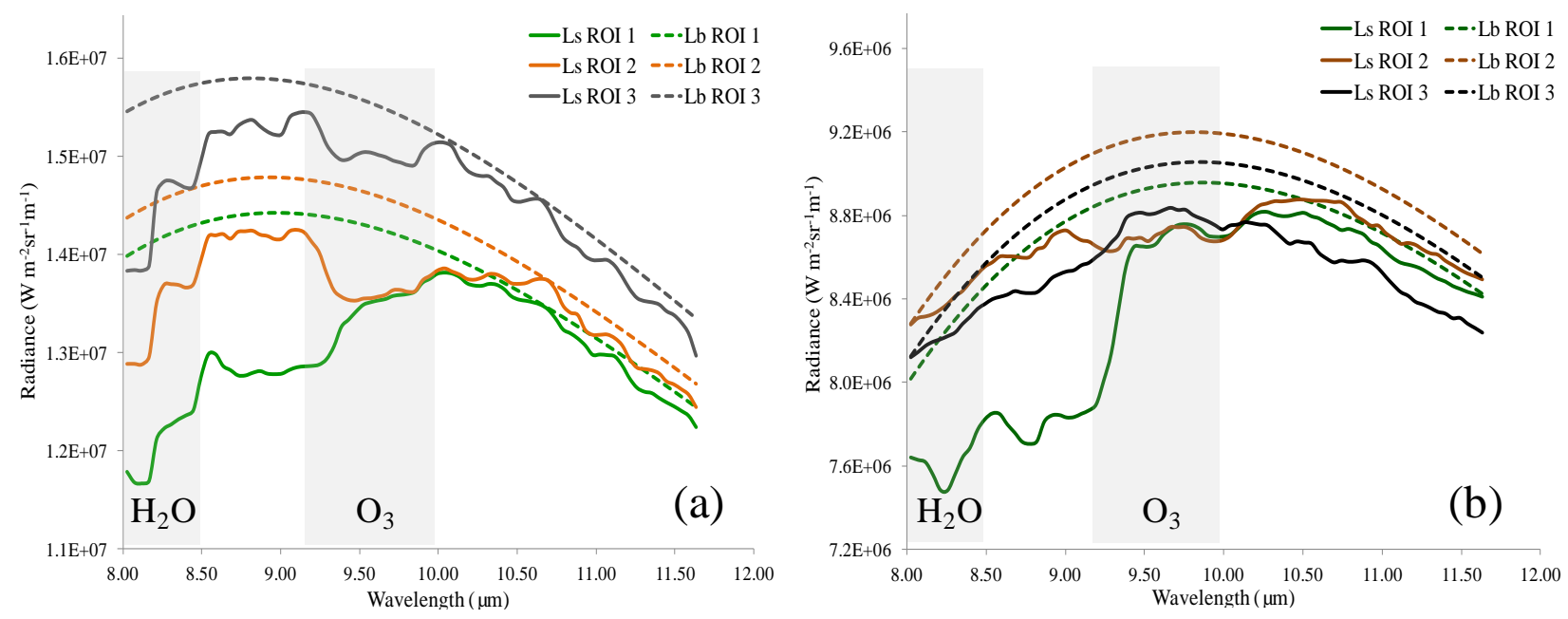

Figure 2. At-sensor radiance (Ls; solid curves) and fitted tangent blackbody radiation (Lb; dashed curves) of three ROIs (representing the three sites from Figure 1b) in (a) day and (b) night images. Gray shading marks the absorption ranges of water vapor $\left(\mathrm{H}_{2} \mathrm{O}\right)$ and ozone $\left(\mathrm{O}_{3}\right)$.

The temperature associated with the blackbody radiation curve of each pixel is considered to be the approximated surface temperature. Day and night temperature images, derived after applying the IDL algorithm to the LWIR images, are shown in Figure 3a,b.

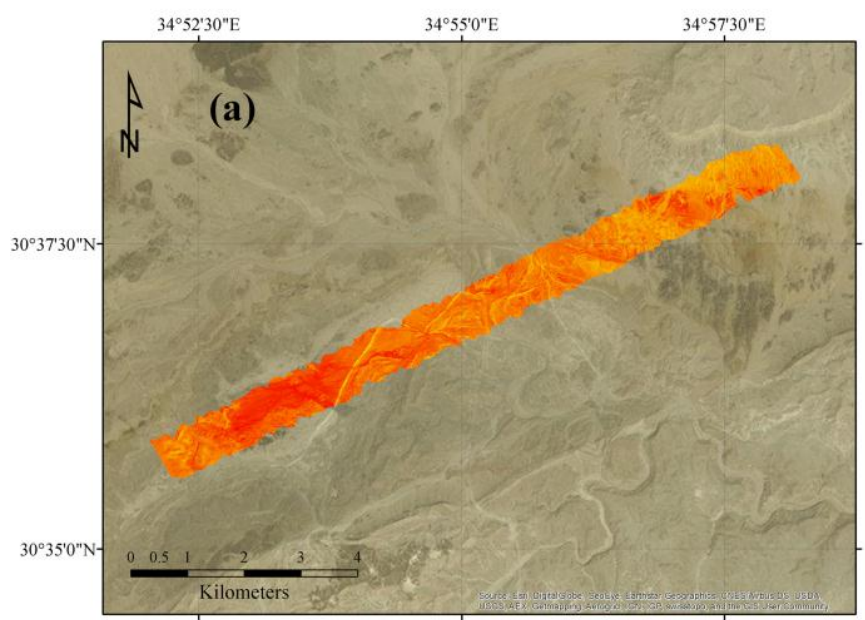

$41-59^{\circ} \mathrm{C}$

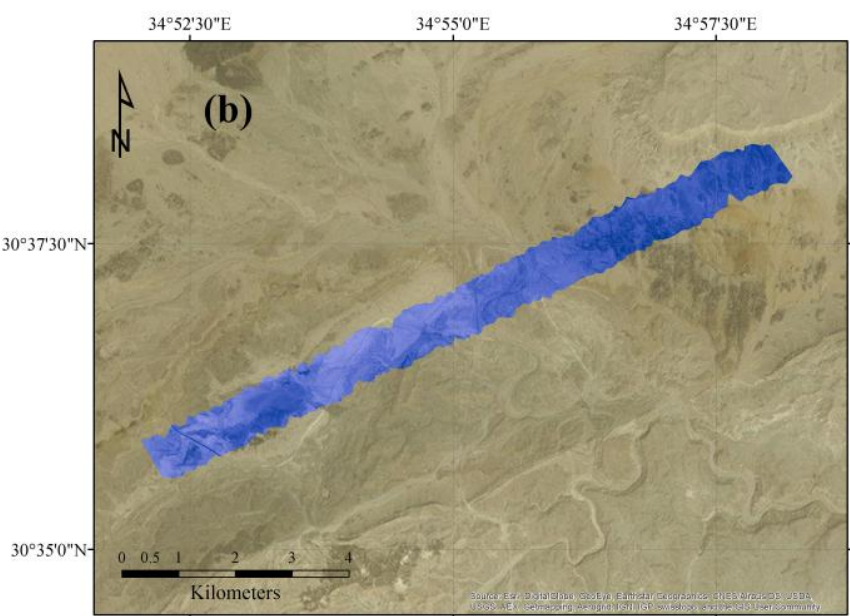

$20-25^{\circ} \mathrm{C}$

Figure 3. (a) Day and (b) night surface temperature images as derived from the LWIR images. The hot surface in the daytime and the cold surface at night, compared to air temperatures of $32-22{ }^{\circ} \mathrm{C}$, respectively, indicate a surface with low thermal inertia, suitable for applying the suggested procedure.

Deviation of the at-sensor radiance from the blackbody curve, as shown in Figure 2a,b, is due to two components: emissivity, expressing the chemical and physical properties of the surface, and the atmospheric contribution, which is expressed by absorption features, such as water vapor and tropospheric ozone, during the day and by emission features at night. Dividing the day and night 
at-sensor radiance (Ls) by the fitted tangent blackbody radiation curve (Lb) resulted in day and night $\mathrm{Ls} / \mathrm{Lb}$ images that emphasize the different atmospheric contributions, i.e., daytime absorption features vs. nighttime emission features, as exemplified in Figure 4a,b. However, the day and night Ls/Lb spectra of each ROI show similar absorption features at specific wavelengths. These noticeable similarities were attributed to surface properties, such as mineral content, assuming no changes in the minerals between the day and night datasets.
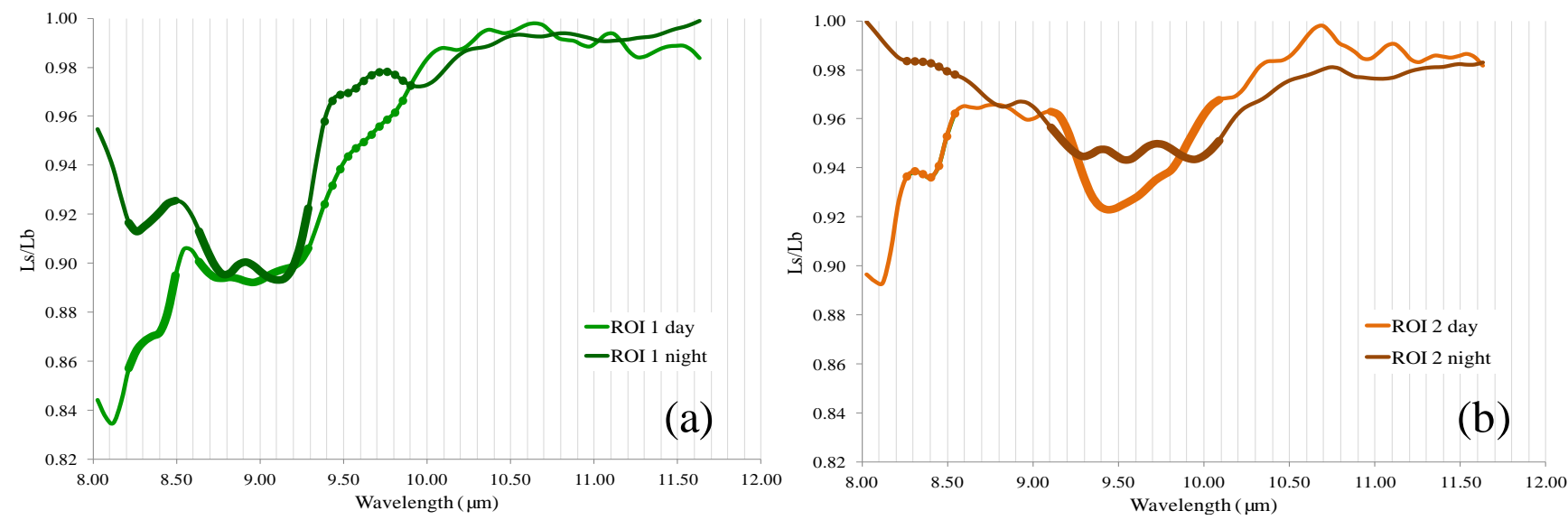

Figure 4. Day and night Ls/Lb spectra of (a) ROI 1 and (b) ROI 2. Different atmospheric contributions are noticeable: ozone's daytime absorption feature vs. nighttime emission feature ((a); dotted lines) and water vapor's daytime absorption feature vs. nighttime emission feature ((b); dotted lines). Similar daytime and nighttime absorption features are noticeable ((a) and (b); thick lines).

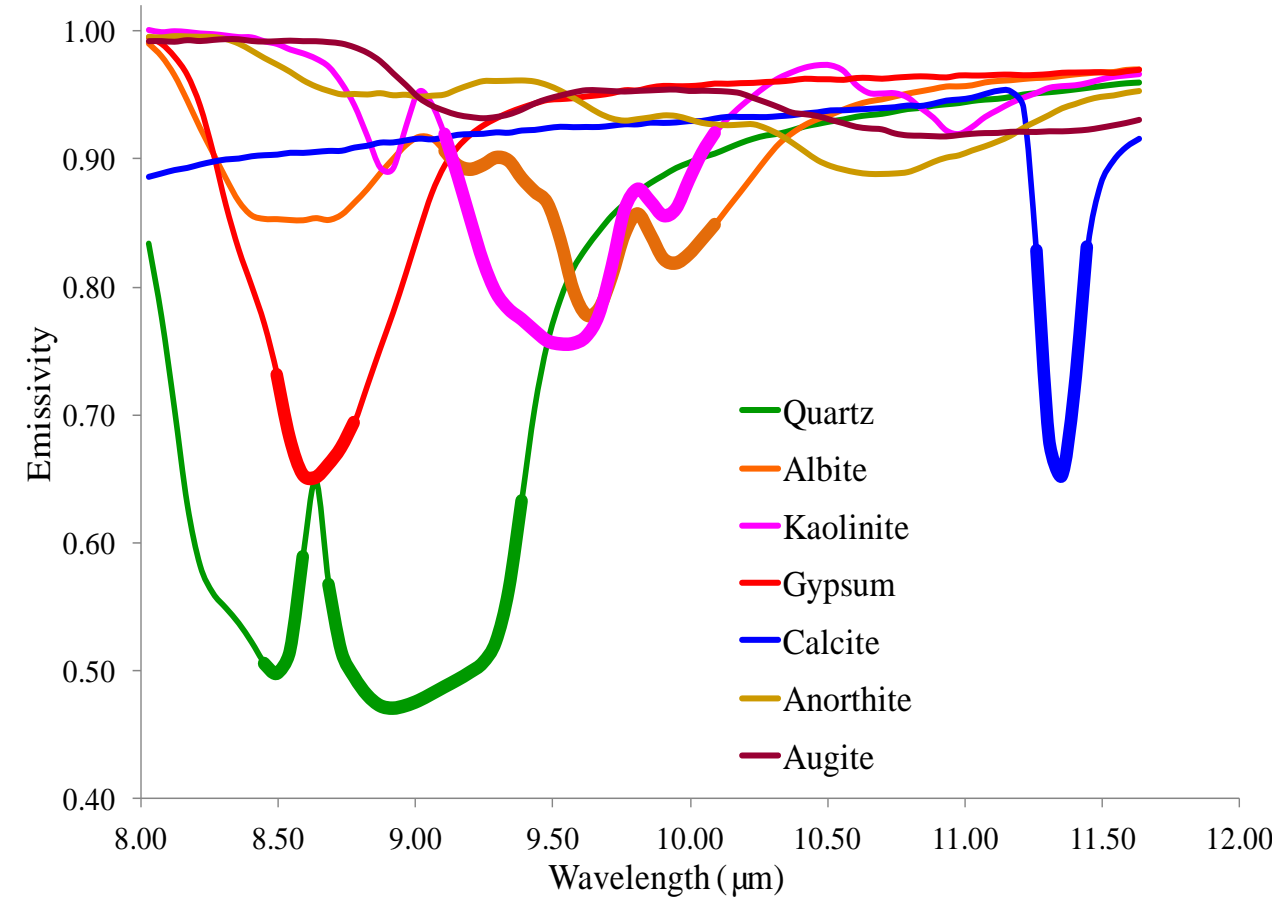

Figure 5. Emissivity spectra of minerals based on [14] and resampled to the AisaOWL spectral configuration. The minerals in the figure are mentioned in the text. Thick lines represent the main mineralogical features. 
Association of the absorption features of both day and night Ls/Lb spectra to known emissivity features of the minerals (Figure 5) - since emissivity expresses the mineral content in the rocks-can indicate the mineralogy of the surface without the need to correct for atmosphere. For example, ROI 1 (Figure 4a), with absorption features between 8.20-8.50 and 8.60-9.30 $\mu \mathrm{m}$ in both day and night spectra, is classified as a quartz-rich rock, whereas ROI 2 (Figure 4b), with an absorption feature between 9.10 and $10.10 \mu \mathrm{m}$ in both spectra, is classified as a silicate (e.g., albite)-rich rock.

\subsubsection{Classification Based on Both Day and Night Images}

The indices described in Table 1 were created with the association to known emissivity features of minerals and were used to identify the presence of specific features in each pixel in the Ls/Lb images. A pixel was classified only if absorption features were present in both day and night images.

Table 1. Mineral indices.

\begin{tabular}{|c|c|}
\hline Mineral & Indices \\
\hline Quartz & $\mathrm{Ls} / \mathrm{Lb}_{\lambda=8.26 \mu \mathrm{m}}{ }^{\mathrm{a}}-\mathrm{Ls} / \mathrm{Lb}_{\lambda=8.54 \mu \mathrm{m}}<0$ and $\mathrm{Ls} / \mathrm{Lb}_{\lambda}=8.54 \mu \mathrm{m}-\mathrm{Ls} / \mathrm{Lb}_{\lambda}=9.10 \mu \mathrm{m}>0$ \\
\hline Silicates ${ }^{b}$ & $\mathrm{Ls} / \mathrm{Lb}_{\lambda}=9.10 \mu \mathrm{m}-\mathrm{Ls} / \mathrm{Lb}_{\lambda=9.43 \mu \mathrm{m}}>0$ and $\mathrm{Ls} / \mathrm{Lb}_{\lambda=9.43 \mu \mathrm{m}}-\mathrm{Ls} / \mathrm{Lb}_{\lambda=10.09}<0$ \\
\hline Gypsum & CR_Ls/Lb $b_{\lambda}=8.68 \mu \mathrm{m}(8.17-9.01)^{c}<0.99$ and $\mathrm{Ls} / \mathrm{Lb}_{\lambda}=8.68 \mu \mathrm{m}-\mathrm{Ls} / \mathrm{Lb} \lambda=9.10 \mu \mathrm{m}<0$ \\
\hline Carbonates & CR_Ls/Lb $b_{\lambda=11.21 \mu \mathrm{m}}(10.98-11.45)<0.995$ \\
\hline
\end{tabular}

a: $\mathrm{Ls} / \mathrm{Lb}$ value at the indicated wavelength; ${ }^{\mathbf{b}}$ : Silicates that are not quartz (feldspars, clay minerals);

c: $\mathrm{Ls} / \mathrm{Lb}$ continuum-removal (CR) value at the indicated wavelength (the CR range is in parentheses).

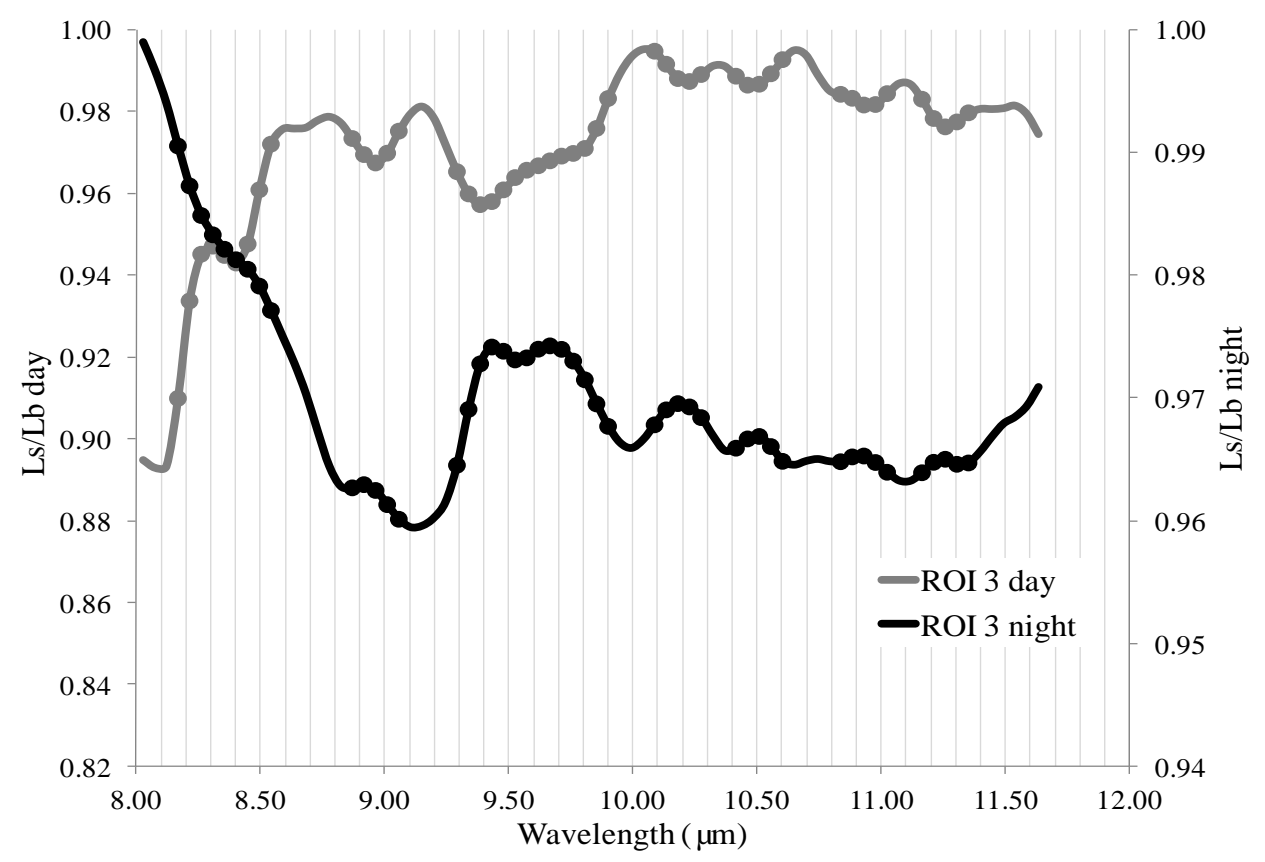

Figure 6. Day (primary y-axis) and night (secondary y-axis) Ls/Lb spectra of ROI 3. The radiation emitted from the warm surface during the day $\left(60{ }^{\circ} \mathrm{C}\right.$, field measurement) was absorbed by the atmosphere, and the atmospheric emission adds to the radiation emitted from the cold surface at night $\left(22^{\circ} \mathrm{C}\right)$. Dotted lines emphasize daytime absorption features $v s$. nighttime emission features. There were no similar daytime and nighttime absorption features at any point along the spectrum. 
One ROI (ROI 3) did not show any day-night similarities in absorption features across the entire $\mathrm{Ls} / \mathrm{Lb}$ spectrum (Figure 6): each absorption feature during the day appeared as an emission at night, namely, each feature could be related to the interaction between surface-emitted radiation and the atmosphere. Therefore, the day or night Ls/Lb spectrum of this surface, representing the contribution of the atmosphere to the at-sensor radiance, can be applied to each pixel in the respective day or night image, reducing the atmospheric features.

\subsubsection{Classification Based on Gain Spectrum}

Once the $\mathrm{Ls} / \mathrm{Lb}$ spectrum representing the atmosphere, henceforth gain spectrum, was found, the spectrum of each pixel in the day or night Ls/Lb image was divided by it (day or night, respectively) to reduce the contribution of the atmosphere and consequently emphasize the spectral features associated with the minerals. The resulting spectrum $(\mathrm{Ls} / \mathrm{Lb}) /($ gain spectrum) could be considered the approximate emissivity spectrum of the pixel. Figure 7 demonstrates the resemblance between day and night approximate emissivity spectra of a ROI with dominant features expressing the mineralogy of the surface-ROI 1 as a quartz-dominant rock and ROI 2 as a silicate-dominant rock. The resemblance appears in the mineral-related features, although not in the absolute values. Therefore, mineral classification can be performed using only one dataset, day or night. In addition, the approximate emissivity features simplify the identification of the major minerals using the indices described in Table 2.

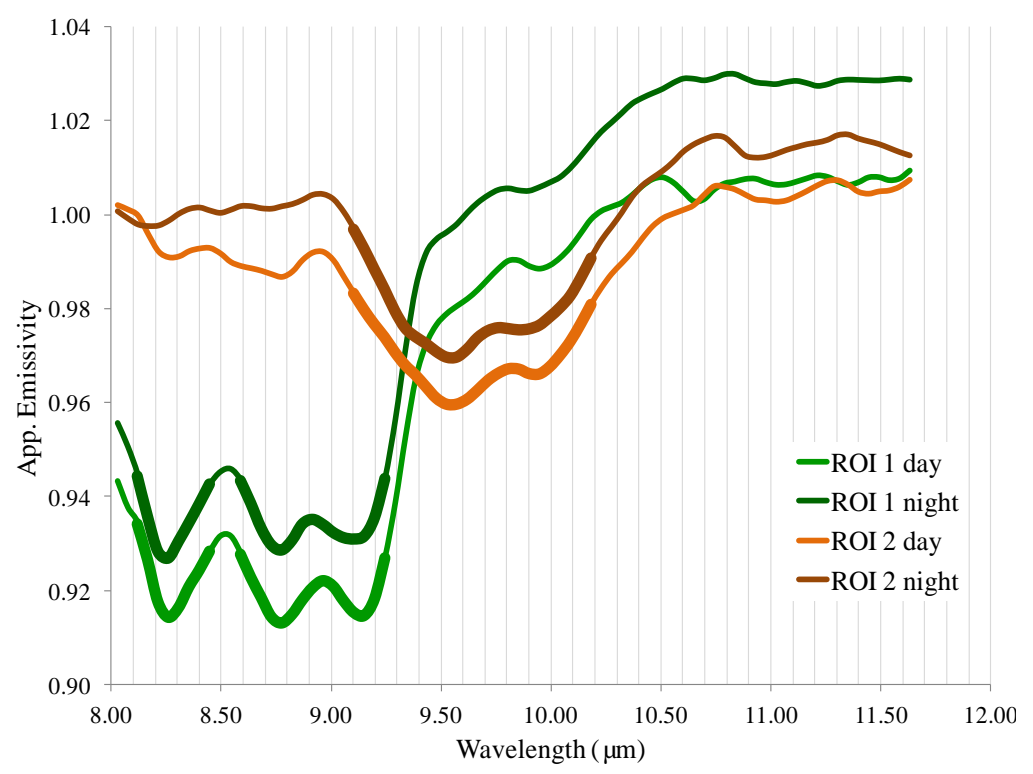

Figure 7. Day and night approximate (App.) emissivity spectra of the two ROIs, 1 and 2. Thick lines represent the mineralogical features.

Table 2. Mineral indices.

\begin{tabular}{cc}
\hline Mineral & Indices \\
\hline Quartz & $\mathrm{CR}_{\lambda=8.26 \mu \mathrm{m}}(8.12-9.29)^{\mathrm{a}}<0.993$ and $\mathrm{CR}_{\lambda=9.15 \mu \mathrm{m}}(8.12-9.29)<0.995$ \\
Silicates & $\mathrm{CR}_{\lambda=9.47 \mu \mathrm{m}}(9.10-10.23)<0.993$ \\
Gypsum & $\mathrm{CR}_{\lambda=8.63 \mu \mathrm{m}}(8.40-8.78)<0.993$ \\
Carbonates & $\mathrm{CR}_{\lambda=11.16 \mu \mathrm{m}}(11.02-11.49)<0.995$ \\
\hline
\end{tabular}

a: App. emissivity continuum-removal (CR) value at the indicated wavelength (the $\mathrm{CR}$ range is in parentheses). 


\section{Results and Discussion}

\subsection{The Straightforward Approach}

As described in Section 2.4.1, pixels in the $\mathrm{Ls} / \mathrm{Lb}$ images were classified as rich in a specific mineral if a corresponding absorption feature (described in Table 1) was identified in both day and night images. The result, a mineralogical map of the surface at the bottom of Makhtesh Ramon, is shown in Figure 8. Classification of the major minerals resembles the XRD analysis results of selected rock samples collected from the study area (Table 3). This procedure has the advantage of simplicity as data processing is performed directly from the at-sensor radiance. However, detectable surface spectral features must be significant and larger than the atmospheric features. In some ROIs, quartz was not identified although it was present in the XRD analysis, mainly in samples for which quartz was not the major mineral. ROI 3, according to Section 2.4.1, could not be classified. Its mineralogy, based on $\mathrm{XRD}$ analysis, is a mixture of silicates with ilmenite $\left(\mathrm{FeTiO}_{3}\right)$, typical to mafic igneous rocks. With dominant atmospheric features, its $\mathrm{Ls} / \mathrm{Lb}$ spectrum was used to reduce the contribution of the atmosphere in all other pixels in the Ls/Lb daytime image, emphasizing the mineral-related features in the Ls/Lb spectra.

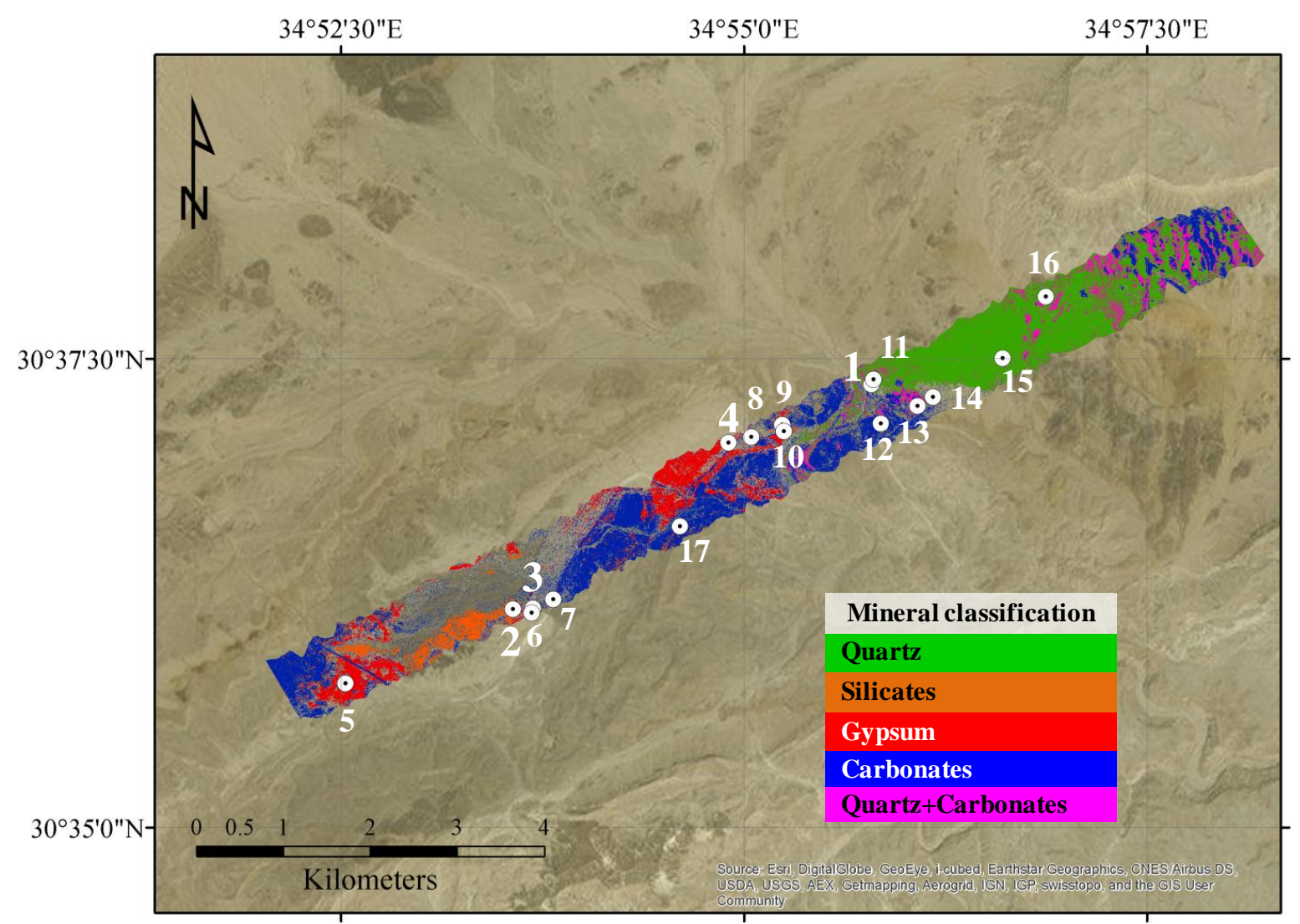

Figure 8. Mineral map of the bottom surface of Makhtesh Ramon. Sampled ROIs are shown and numbered (including ROIs 1, 2 and 3 from Section 2.4). 
Table 3. Mineral classification-HRS analysis $v s$. XRD analysis.

\begin{tabular}{|c|c|c|c|}
\hline ROI & HRS Analysis a & $\begin{array}{c}\text { XRD Analysis } \\
\text { (from Major to Minor) }^{\mathbf{b}}\end{array}$ & HRS Analysis ${ }^{c}$ \\
\hline 1 & Quartz & Quartz, Calcite, Dolomite, Kaolinite, Iron oxides & Quartz \\
\hline 2 & Silicates & Albite-low, Quartz, Clinochlore & Silicates, Quartz \\
\hline 3 & Not classified & Anorthite, Albite, Quartz, Ilmenite, Augite & --- \\
\hline 4 & Gypsum, Carbonates & $\begin{array}{c}\text { Gypsum, Quartz, Dolomite, Calcite, Iron oxides, } \\
\text { Titanium dioxide }\end{array}$ & Gypsum, Carbonates, Quartz \\
\hline 5 & Gypsum & Gypsum, Quartz, Brushite & Gypsum, Quartz \\
\hline 6 & Gypsum, Carbonates & Quartz, Gypsum, Calcite, Dolomite, Brushite & Gypsum, Carbonates \\
\hline 7 & Carbonates & Calcite, Quartz & Carbonates, Quartz \\
\hline 8 & Carbonates, Gypsum & $\begin{array}{c}\text { Dolomite, Gypsum, Calcite, Quartz, Kaolinite, } \\
\text { Titanium dioxide }\end{array}$ & Carbonates, Gypsum, Quartz \\
\hline 9 & Carbonates & Calcite, Quartz, Dolomite, Kaolinite, Iron oxides & Carbonates, Quartz \\
\hline 10 & Silicates & Calcite, Kaolinite, Quartz, Dolomite, Iron oxides & Silicates \\
\hline 11 & Quartz & Quartz, Calcite, Kaolinite, Iron oxides & Quartz \\
\hline 12 & Carbonates & Calcite, Quartz, Dolomite, Kaolinite & Carbonates, Quartz \\
\hline 13 & Quartz, Carbonates & Quartz, Calcite, Kaolinite, Dolomite, Iron oxides & Quartz, Carbonates \\
\hline 14 & Carbonates & Calcite, Quartz, Dolomite, Kaolinite, Iron oxides & Quartz, Carbonates \\
\hline 15 & Quartz & Quartz, Calcite, Iron oxides & Quartz \\
\hline 16 & Quartz, Carbonates & Calcite, Quartz, Kaolinite, Iron oxides, Dolomite & Quartz, Carbonates \\
\hline 17 & Carbonates, Silicates & Calcite, Quartz, Dolomite, Albite & Carbonates, Silicates, Quartz \\
\hline
\end{tabular}

\subsection{The Gain Spectrum Approach}

As described in Section 2.4.2, pixels in the approximate emissivity daytime image were classified as rich in specific minerals using the indices in Table 2. Figure 9 shows the mineral classification after correction with the gain spectrum. The basic mineralogy is similar to that described in Figure 8 . However, in some areas, quartz was identified in addition to other minerals. This is exemplified in Figure 10 for a ROI (ROI 4) that was classified as gypsum- and carbonate-rich rock according to the straightforward approach (Figure 10a) and as gypsum-, carbonate- and quartz-rich rock after correction with the gain spectrum (Figure 10b). The classification of other ROIs and the resemblance to the XRD analysis results are shown in Table 3. The resulting map of the major minerals is in agreement with the geological map of the area, as shown in Figure 9. Across the flight line (southwest to northeast), the mineralogy changes from gypsum- and carbonate-rich rocks (Mohila formation "tr3"), interrupted by intrusion of volcaniclastic rocks ("im") containing silicates (feldspars, "mafic" minerals and quartz), to quartz-rich rocks (Inmar formation "j12") and quartz- and carbonate-rich rocks in the northeast part (Kurnub group "lck"). The presence of carbonates in the northeast part demonstrates the contribution of weathering processes occurring in Har Ardon (Hevyon formation "c1", outside the flight line) with an elevation of $700 \mathrm{~m}$ above sea level, adding carbonates to the lower quartz-rich plains (500 $\mathrm{m}$ above sea level). It should be emphasized that quartz and other silicates (mainly feldspars) are featureless in the VNIR-SWIR spectral region, and therefore these minerals can only be 
identified with a LWIR sensor. The sub-classification of feldspars $v s$. clay was based on the wavelength of the silicate feature, $9.57 \mu \mathrm{m}$ for feldspars $v s .9 .29 \mu \mathrm{m}$ for clay minerals, as exemplified in Figure 11 (and in accordance with Figure 5).

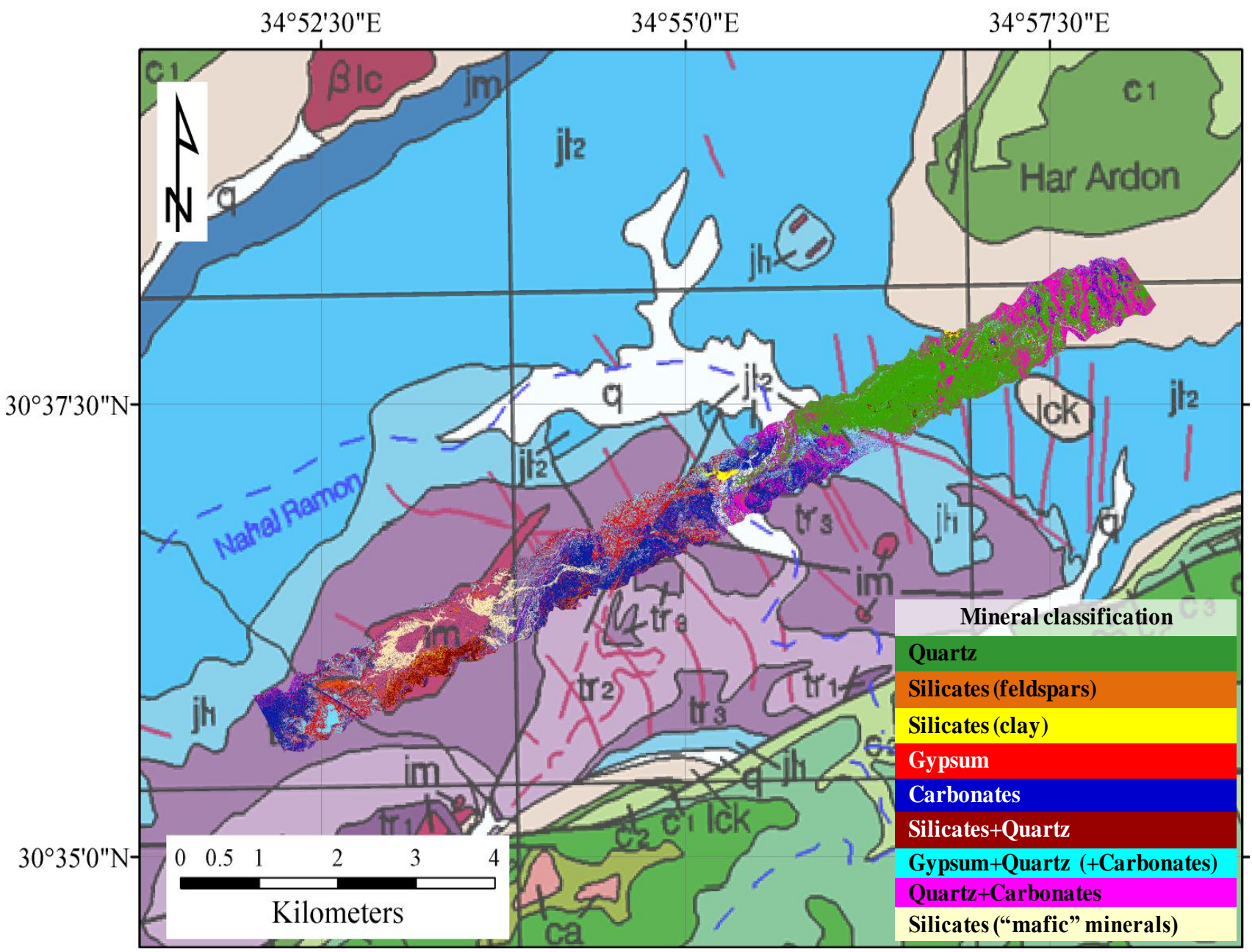

\begin{tabular}{|c|c|}
\hline Symbol & Geology \\
\hline Blc & Basalt flows (Basalt, basanite, tephrite, nephelinite) Lower Cretaceous \\
\hline $\mathrm{cl}$ & Hevyon Fm. (Limestone, dolostone, marl, chert, sandstone 44 m) Albian-Cenomanian \\
\hline c2 & En Yorqe'am, Zafit and Avnon fms. (Limestone, dolostone, marl, chert $124 \mathrm{~m}$ ) Cenomanian \\
\hline im & Intrusions and volcaniclastic rocks (Basalt) Mesozoic \\
\hline j11 & Mishor and Ardon fms. (Dolostone, limestone, clay, standstone $21 \mathrm{~m}$ ) Lower Jurassic \\
\hline j12 & Inmar Fm. (Sandstone, clay $120 \mathrm{~m}$ ) Lower Jurassic \\
\hline jm & Mahmal, Zohar and Matmor fms. (Sandstones, limestones, marl, clay) Middle Jurassic \\
\hline lck & Kurnub Group (Sandstone, mudstone, clay, pebbly sandstone, conglomerate $240 \mathrm{~m}$ ) Lower Cretaceous \\
\hline q & Alluvium (Gravel, sand, silt) Quaternary \\
\hline $\operatorname{tr} 1$ & Gevanim Fm. (Sandstone, limestone, siltstone, clay $68 \mathrm{~m}$ ) Lower Triassic \\
\hline $\operatorname{tr} 2$ & Saharonim Fm. (Limestone, clay, marl, dolostone, sandstone, gypsum $117 \mathrm{~m}$ ) Middle Triassic \\
\hline $\operatorname{tr} 3$ & Mohila Fm. (Gypsum, dolostone, limestone, clay 202 m) Upper Triassic \\
\hline
\end{tabular}

Figure 9. Mineral map of the bottom surface of Makhtesh Ramon. The "mafic" minerals refer to mineralogy similar to ROI 3 which was mapped by applying the Spectral Angle Mapper algorithm [15] with the ROI 3 Ls/Lb spectrum as the endmember spectrum. 

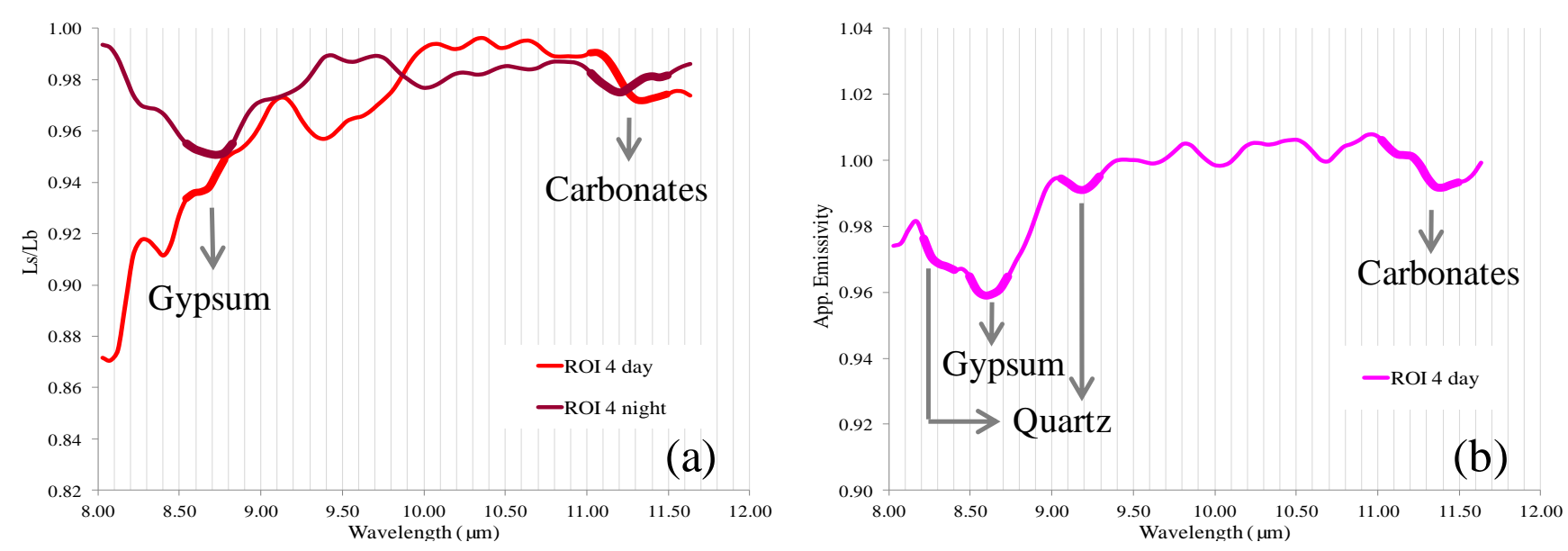

Figure 10. (a) Ls/Lb spectra and (b) approximate emissivity spectrum of ROI 4. The relevant features are emphasized with thick lines for the identified minerals.

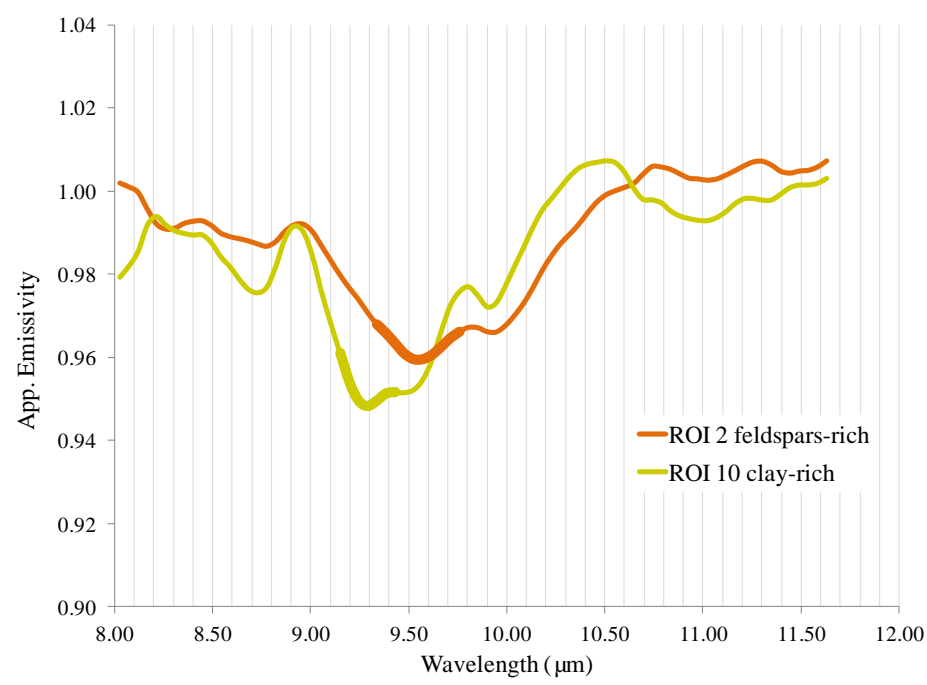

Figure 11. Approximate emissivity spectrum of two ROIs representing two types of silicates-rich rocks. The relevant features are emphasized with thick lines for the identified minerals.

\section{Summary and Conclusions}

Dozens of scientific papers and reports have been published on geology, climatology, ecology and HRS studies of the Makhtesh Ramon area [16-21]. The current study presents the first airborne LWIR HRS campaign in this area, with the AisaOWL hyperspectral sensor. The ability to detect quartz, other silicates (feldspars and clay minerals), gypsum and carbonates in the LWIR region (8-12 $\mu \mathrm{m}$ spectral range) enabled mapping the spatial distribution of the dominant minerals in the bottom surface of Makhtesh Ramon. It should be mentioned that quartz and feldspars can only be mapped using the LWIR HRS data since the silicon-oxygen bond ( $\mathrm{Si}-\mathrm{O})$ stretching vibrations in quartz and feldspars, as well as in other silicates, exhibit spectral features only in TIR, mainly in the LWIR region [22-24], whereas clay minerals, gypsum and carbonates can also be detected in the SWIR spectral region. The proposed approach is based on the fact that the contribution of the atmosphere to the at-sensor radiance measured from the surface is expressed differently during the day and at night. 
In the daytime, the radiation emitted from the warmer surface is absorbed by the atmosphere whereas at night, when the surface becomes as cold as (or colder than) the atmosphere, the emission from the gases adds to the radiation emitted from the surface. The at-sensor radiance (Ls) of each pixel in the day and night images was divided by a fitted tangent blackbody radiation curve (Lb). The identification of spectral features in both day and night Ls/Lb spectra enabled mapping the content of minerals in the surface. Such features must be significant and larger than atmospheric features to be identified. The resultant mineralogy, including quartz, other silicates, gypsum and carbonates, was in quite good agreement with the mineralogy of selected rock samples which were collected from the study area as derived from XRD analysis. The Ls/Lb spectrum of a specific surface was selected as the gain spectrum because there were no spectral similarities between day and night over the entire spectral range, only atmospheric features. The spectrum of each pixel in the Ls/Lb image was divided by the gain-factor to reduce the atmospheric contribution, emphasize the mineralogical features in each pixel and improve the mineral classification. The resulting mineral image, classifying the major minerals in each pixel, was in agreement with the geological map of the area.

The proposed procedure is a direct approach, with no need to correct for atmosphere, although it might not be applicable to fine mineralogical classification and depends on acquiring both day and night images. Alternatively, once an in situ surface presenting the atmosphere's contribution is known to be present in the study area, its radiance can be used to calculate an approximated emissivity from a day or night image. Such a surface, with a featureless emissivity spectrum, should be characterized by low thermal inertia so that the radiation emitted from the warmer surface during the day is absorbed by the atmosphere, or the atmospheric emission adds to the radiation emitted from the colder surface at night. In this way, atmospheric features can be identified in the at-sensor radiance measured from the surface.

\section{Acknowledgments}

This study was supported by the Israeli Ministry of Science, Technology and Space fund 00040047000 grant No. 3-8163.

\section{Author Contributions}

Gila Notesco processed the airborne and ground data, analyzed the results, and is the main author of the article. Yaron Ogen helped with the geological maps and their interpretation. Eyal Ben-Dor was the project supervisor and participated in all stages of the work.

\section{Conflicts of Interest}

The authors declare no conflict of interest.

\section{References}

1. Rowan, L.C.; Mars, J.C. Lithologic mapping in the Mountain Pass, California area using Advanced Spaceborne Thermal Emission and Reflection Radiometer (ASTER) data. Remote Sens. Environ. 2003, 84, 350-366. 
2. Vaughan, R.G.; Calvin, W.M.; Taranik, J.V. SEBASS hyperspectral thermal infrared data: Surface emissivity measurement and mineral mapping. Remote Sens. Environ. 2003, 85, 48-63.

3. Hook, S.J.; Dmochowski, J.E.; Howard, K.A.; Rowan, L.C.; Karlstrom, K.E.; Stock, J.M. Mapping variations in weight percent silica measured from multispectral thermal infrared imagery-Examples from the Hiller Mountains, Nevada, USA and Tres Virgenes-La Reforma, Baja California Sur, Mexico. Remote Sens. Environ. 2005, 95, 273-289.

4. Ninomiya, Y.; Fu, B.; Cudahy, T.J. Detecting lithology with Advanced Spaceborne Thermal Emission and Reflection Radiometer (ASTER) multispectral thermal infrared "radiance-at-sensor" data. Remote Sens. Environ. 2005, 99, 127-139.

5. Eisele, A.; Lau, I.; Hewson, R.; Carter, D.; Wheaton, B.; Ong, C.; Cudahy, T.J.; Chabrillat, S.; Kaufmann, H. Applicability of the thermal infrared spectral region for the prediction of soil properties across semi-arid agricultural landscapes. Remote Sens. 2012, 4, 3265-3286.

6. Gillespie, A.; Rokugawa, S.; Matsunaga, T.; Cothern, J.S.; Hook, S.; Kahle, A.B. A temperature and emissivity separation algorithm for Advanced Spaceborne Thermal Emission and Reflection Radiometer (ASTER) images. IEEE Trans. Geosci. Remote Sens. 1998, 36, 1113-1126.

7. Coll, C.; Caselles, V.; Rubio, E.; Sospedra, F.; Enric Valor, E. Temperature and emissivity separation from calibrated data of the digital airborne imaging spectrometer. Remote Sens. Environ. 2001, 76, 250-259.

8. Cheng, J.; Liang, S.; Wang, J.; Li, X. A Stepwise refining algorithm of temperature and emissivity separation for hyperspectral thermal infrared data. IEEE Trans. Geosci. Remote Sens. 2010, 48, 1588-1597.

9. Young, S.J.; Johnson, B.R.; Hackwell, J.A. An in-scene procedure for atmospheric compensation of thermal hyperspectral data. J. Geophys. Res. 2002, 107, 4774-4793.

10. Evenari, M.; Shanan, L.; Tadmor, N. The Negev: The Challenge of a Desert; Harvard University Press: Cambridge, MA, USA, 1982.

11. The Specim AisaOWL System. Available online: http://www.specim.fi/index.php/products/ airborne/aisaowl (accessed on 14 June 2015).

12. The Israel Meteorological Service. Available online: http://www.ims.gov.il (accessed on 14 June 2015).

13. Notesco, G.; Kopačková, V.; Rojík, P.; Schwartz, G.; Livne, I.; Ben Dor, E. Mineral classification of land surface using multispectral LWIR and hyperspectral SWIR remote-sensing data: A case study over the Sokolov Lignite Open-Pit Mines, the Czech Republic. Remote Sens. 2014, 6, 7005-7025.

14. The Arizona State University Spectral Library. Available online: http://speclib.asu.edu (accessed on 14 June 2015).

15. Kruse, F.A.; Lefkoff, A.B.; Boardman, J.W.; Heidebrecht, K.B.; Shapiro, A.T.; Barloon, P.J.; Goetz, A.F.H. The spectral image processing system (SIPS) - Interactive visualization and analysis of imaging spectrometer data. Remote Sens. Environ. 1993, 44, 145-163.

16. Nativ, R.; Mazor, E. Rain events in an arid environment-Their distribution and ionic and isotopic composition patterns: Makhtesh Ramon Basin, Israel. J. Hydrol. 1987, 89, 205-237. 
17. Kaufman, H.; Weisbrich, W.; Beyth, M.; Bartov, Y.; Itamar, A.; Ronen, S.; Kafri, U. Mineral identification using GER-II data acquired from Makhtesh Ramon/Negev, Israel. EARSeL Adv. Remote Sens. 1991, 1, 82-92.

18. Lawes, M.J.; Nanni, R.F. The density, habitat use and social organisation of Dorcas Gazelles (Gazella dorcas) in Makhtesh Ramon, Negev Desert, Israel. J. Arid Environ. 1993, 24, 177-196.

19. Ben Dor, E.; Kruse, F.A. Surface mineral mapping of Makhtesh Ramon Negev, Israel using GER 63 channel scanner data. Int. J. Remote Sens. 1995, 16, 3529-3553.

20. Anker, Y.; Ben Dor, E.; Zelikman, E.; Karnieli, A.; Mazor, E. Makhtesh Ramon, a super site for calibration and validation of IS sensors. In Proceedings of the 6th EARSeL SIG Workshop on Imaging Spectroscopy, Tel Aviv, Israel, 16-18, March 2009.

21. Guanter, L.; Segl, K.; Kaufmann, H. Simulation of optical remote-sensing scenes with application to the EnMAP hyperspectral mission. IEEE Trans. Geosci. Remote Sens. 2009, 47, 2340-2351.

22. Salisbury, J.W.; D'Aria, D.M. Emissivity of terrestrial materials in the 8-14 $\mu \mathrm{m}$ atmospheric window. Remote Sens. Environ. 1992, 42, 83-106.

23. Christensen, P.R.; Bandfield, J.L.; Hamilton, V.E.; Howard, D.A.; Lane, M.D.; Piatek, J.L.; Ruff, S.W.; Stefanov, W.L. A thermal emission spectral library of rock-forming minerals. J. Geophys. Res. 2000, 105, 9735-9739.

24. Baldridge, A.M.; Hook, S.J.; Grove, C.I.; Rivera, G. The ASTER spectral library version 2.0. Remote Sens. Environ. 2009, 113, 711-715.

(C) 2015 by the authors; licensee MDPI, Basel, Switzerland. This article is an open access article distributed under the terms and conditions of the Creative Commons Attribution license (http://creativecommons.org/licenses/by/4.0/). 